\title{
Phasic increases in cortical beta activity are associated with alterations in sensory processing in the human
}

Elodie Lalo • Thomas Gilbertson • Louise Doyle •

Vincenzo Di Lazzaro • Beatrice Cioni • Peter Brown

Published online: 10 January 2007

(C) Springer-Verlag 2007

\section{Erratum to: Exp Brain Res}

DOI 10.1007/s00221-006-0655-8

The name of the author Vincenzo Di Lazzaro is not published correct in the authors addresses in the pdf online and printed version.

The correct name is V. Di Lazzaro.

The online version of the original article can be found at http://dx.doi.org/10.1007/s00221-006-0655-8.

E. Lalo · T. Gilbertson · L. Doyle · P. Brown $(\bowtie)$ Sobell Department of Motor Neuroscience and Movement

Disorders, Institute of Neurology, Queen Square,

London WC1N 3BG, UK

e-mail: p.brown@ion.ucl.ac.uk

V. Di Lazzaro

Institute of Neurology, Università Cattolica,

00168 Rome, Italy

B. Cioni

Institute of Neurosurgery, Università Cattolica,

00168 Rome, Italy 